\title{
LOUVRE FLAPS FOR FINGER DEFECTS IN HAND INJURIES
}

\author{
Ratna Bhushan Badugu1, Kathi Srinath²
}

${ }^{1}$ Assistant Professor, Department of Plastic Surgery, KGH/Andhra Medical College, Maharanipet, Visakhapatnam, Andhra Pradesh. ${ }^{2}$ Assistant Professor, Department of Plastic Surgery, MNJ Institute of Oncology, Red Hills, Nampally, Hyderabad, Telangana.

\section{ABSTRACT}

\section{BACKGROUND}

Wound coverage after degloving injury of the hand and fingers is the most difficult problem in hand surgery. The vital and delicate structures such as tendons, nerves and bones are exposed. These degloving injuries are significant in hand as quality of skin lost is irreplaceable. ${ }^{1}$ The goal of treatment should be early coverage to regain form and function that will allow early mobilisation.

\section{MATERIALS AND METHODS}

Between January 2011 and January 2014 in Osmania General Hospital, thirty two patients were treated with Louvre abdominal flaps for degloving injuries of fingers due to various causes.

\section{RESULTS}

Louvre abdominal flaps ${ }^{2}$ are versatile in reconstruction of hand injuries with defects in multiple fingers with less donor site morbidity. These flaps help in early return to the work and shortcuts the multiple procedures such as syndactyly release, flap thinning or physiotherapy. Surgical recovery is faster with these flaps.

\section{CONCLUSION}

Louvre flap is a versatile flap to cover each finger separately and simultaneously, provides more tissue than a single flap and leaves a cosmetically better donor site defect.

\section{KEYWORDS}

Degloving Hand Injuries, Reconstruction of Hand, Flaps, Surgical Recovery.

HOW TO CITE THIS ARTICLE: Badugu RB, Srinath K. Louvre flaps for finger defects in hand injuries. J. Evolution Med. Dent. Sci. 2017;6(20):1627-1631, DOI: 10.14260/Jemds/2017/356

\section{BACKGROUND}

First described by A. J. J. Emmett in 1965. Louvre ${ }^{3}$ (British English) is a window blind or shutter with horizontal slats that are angled to admit light and air, but to keep out rain and direct sunshine as these flaps resembles so called Louvre flaps.

Hand injuries with multiple defects involving multiple fingers are more common and pose a challenge to reconstructive surgeon. They may or may not be associated with fractures of fingers. Such defects should be debrided and reconstructed early with flap cover. Usually, such defects are reconstructed by converting multiple defects into a single defect and flap cover was given by creating a syndactyly. But it delays patient returning to work as it involves multiple procedures like syndactyly release, flap thinning and physiotherapy is also delayed.

The causes of finger defects are due to various reasons. They include road traffic accidents, burns, machine injuries, post inflammatory defects. Flap cover is the best choice of cover for finger defects as they prevent adherent scars, contractures which restrict function of the fingers and thin flaps are cosmetically acceptable.

Financial or Other, Competing Interest: None.

Submission 01-02-2017, Peer Review 25-02-2017,

Acceptance 03-03-2017, Published 09-03-2017.

Corresponding Author:

Dr. Ratna Bhushan Badugu,

Flat No. 305, Peela Homes,

HB Colony, Old Venkojipalem,

Visakhapatnam-530022, Andhra Pradesh.

E-mail: ratna_gudivada@yahoo.com

DOI: $10.14260 /$ jemds $/ 2017 / 356$

The Louvre abdominal flaps shortcuts, all procedures of single flaps forming syndactyly of fingers. Louvre flaps are multiple abdominal flaps at the same time for coverage of defects on different fingers.

\section{Aim}

To reconstruct each finger defect separately with multiple abdominal flaps simultaneously rather than single flap to all fingers.

\section{MATERIALS AND METHODS}

Louvre flap was used in thirty two patients from January 2011 to January 2014 in Osmania General Hospital, Hyderabad, Andhra Pradesh.

The age of the patients ranges from 7 years to 42 years. Both female and males are presented with hand injuries. The hand injuries are due to various reasons.

The Defects of hand are due to different reasons. These Includes -

- Post traumatic degloving injury in the fourteen patients.

- Electric burn injury in twelve patients.

- Post burn contracture released defects in four patients.

- Cell phone blast injury in one case.

- Post cellulitis defect in one patient.

\begin{tabular}{|c|c|c|}
\hline Sl. No. & Nature of Injury & No. of Cases \\
\hline 1 & $\begin{array}{c}\text { Deglove Injury } \\
\text { (RTA/Machine Injury) }\end{array}$ & 14 \\
\hline 2 & Electrical Burns & 12 \\
\hline 3 & Blast Injury (Mobile Phone) & 1 \\
\hline 4 & Post Burn Contracture & 4 \\
\hline 5 & $\begin{array}{c}\text { Post Cellulitis Raw Area } \\
\text { (Snakebite) }\end{array}$ & 1 \\
\hline \multicolumn{3}{|c|}{} \\
\hline
\end{tabular}




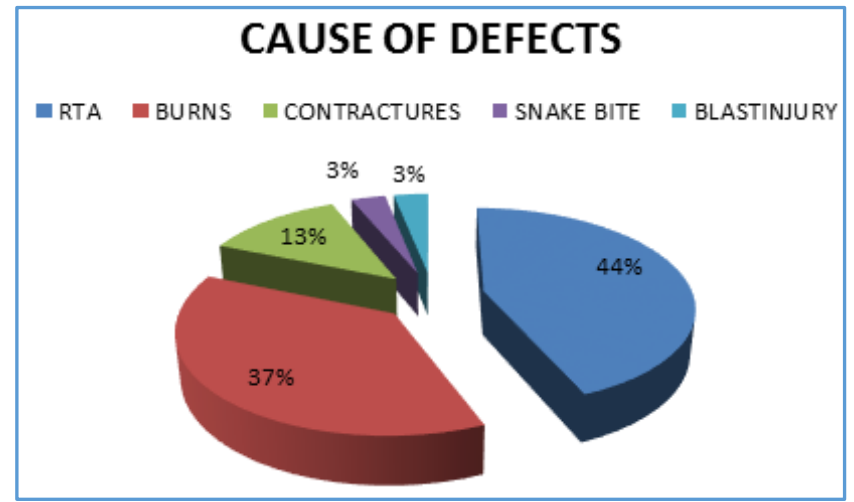

\section{Inclusion Criteria}

- Hand injuries with defects on fingers with exposed tendons or bones.

\section{Exclusion Criteria}

- Hand injuries with site of defects other than fingers.

\section{Examination}

- Flap cover starts with examination of injured limb.

- Which Hand involved.

- Number and site of fingers involved.

- Defects size (True skin loss).

- Any associated vascular compromise/fractures/tendon injuries/joint injuries.

\section{Counselling and Consent}

- Explaining nature of injury to the patient.

- Reconstruction plan outlined.

- Multiple stages of plan explained.

- Total duration of all stages.

- Total hospital stay required for various stages.

- Anaesthesia required.

- Complications of surgery and anaesthesia.

- Resultant scars.

- Valid written consent taken.

- Investigations.

- Surgical profile, radiological films and clinical photographs are routinely done.

\section{Planning}

Management of these defects starts with stable bone fixation, vascular repair, tendon and any nerve repair if any of those injuries before starting flap cover.

We considered step ladder abdominal flaps as ideal and more practical cover in such cases in view of unavailability of microsurgery infrastructure.

\section{Execution of Flaps}

Thorough debridement of defects is an important step; then starts the reconstruction steps.

Louvre flaps are random based abdominal flaps. Though these flaps are ideal for cover of extensor aspect finger defects, we used these flaps to cover lateral and flexor aspect of the fingers too. In all cases we used donor site from the abdomen, though opposite thigh and arm also described in other studies.

Markings of the flaps are done by placing the hand on the abdomen. Flaps planned in maximum position of ease following the orientation of the fingers. They are designed in
1:1 ratio of length and breadth. As the length of the finger defect forms the width of the flap, the width of the flap is designed wider. The plane of flap is just under the dermis, leaving a single layer of subcutaneous fat. Vascular supply of these flaps is from dermal vascular network. The donor sites are closed primarily or skin grafted.

Position of hand checked multiple times before flap inset. The flap inset is given in the best position of ease to the patient. Flaps are sutured to the one edge of the defect with half buried horizontal mattress sutures with knot on finger side. Maximum possible inset to the margin of the defect given. Flap inset given in the position of comfort. Elbow and arm restraints are applied. Dressings are managed carefully. Immobilisation of hand strictly followed for $24-48 \mathrm{hrs}$. and ambulated once patient is comfortable.

Postoperatively, cleaning of the suture line with antiseptic solution done on a daily basis. Soiled gauzes at exposed raw area were replaced frequently with clean gauze of antibiotic ointment. If skin grafting done, donor site was managed carefully with sterile non-adhesive compressive bandages.

Flaps are delayed at $2-3$ weeks and divided after a week. Exact line of division of the flap marked and planned for delay and division of flap. Final inset is given after division of the flap. A good inset given after debridement of the skin defect on the finger. If any wound at abdomen, closed with graft or secondary suturing.

Once flaps were divided, a volar POP slap applied with hand in neutral position. After drying up of wound in a week or 10 days, individual finger movements are encouraged by discarding splints and followed the patient frequently as needed. At the end of three weeks, straight splints for fingers were advised to prevent flexion contractures. Physiotherapy was advised to all the patients to improve and regain normal function of the hand. Scar massages and compression garments are used to make scars soft and supple.

Louvre flaps are used frequently to extensor aspect of fingers or lateral surface defects with ease. But in one case, we used for flexor surface too. Both contralateral and ipsilateral abdominal flaps are planned. Superiorly and inferiorly based flaps are used depending on the site of defect and comfort of the hand.

Patients were followed for 3 - 6 months. Almost all patients regained their normal function of the hand by $3-4$ months after flap division with strict physiotherapy.

No complications such as infections, wound dehiscence, flap necrosis has occurred in any cases.

\section{RESULTS}

These flaps resulted in thin, pliable and cosmetically pleasing flaps. Donor site scarring is also well accepted by patients. Early mobilisation ${ }^{4}$ of fingers and immediate physiotherapy is the main advantage we observed.

These flaps does not require other procedures as in single flaps used for finger defects such as syndactyly release, web creation or debulking of flaps.

- Fortunately, no complications such as flap necrosis, wound dehiscence or infections occurred in any of the cases.

- Good hand function was regained with strict physiotherapy.

- Average recovery period ranged from 3 months to 4 months with mean followup of 3 - 6 months. 
Jemds.com

Case 1
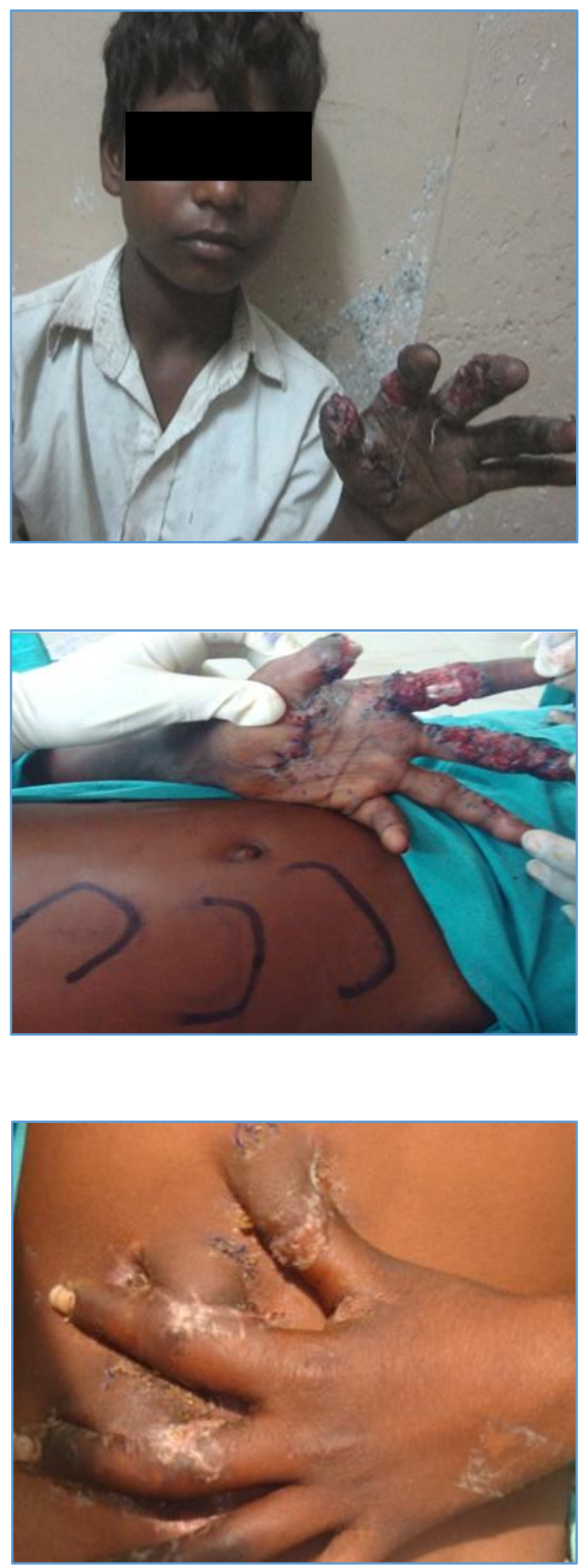

Original Research Article

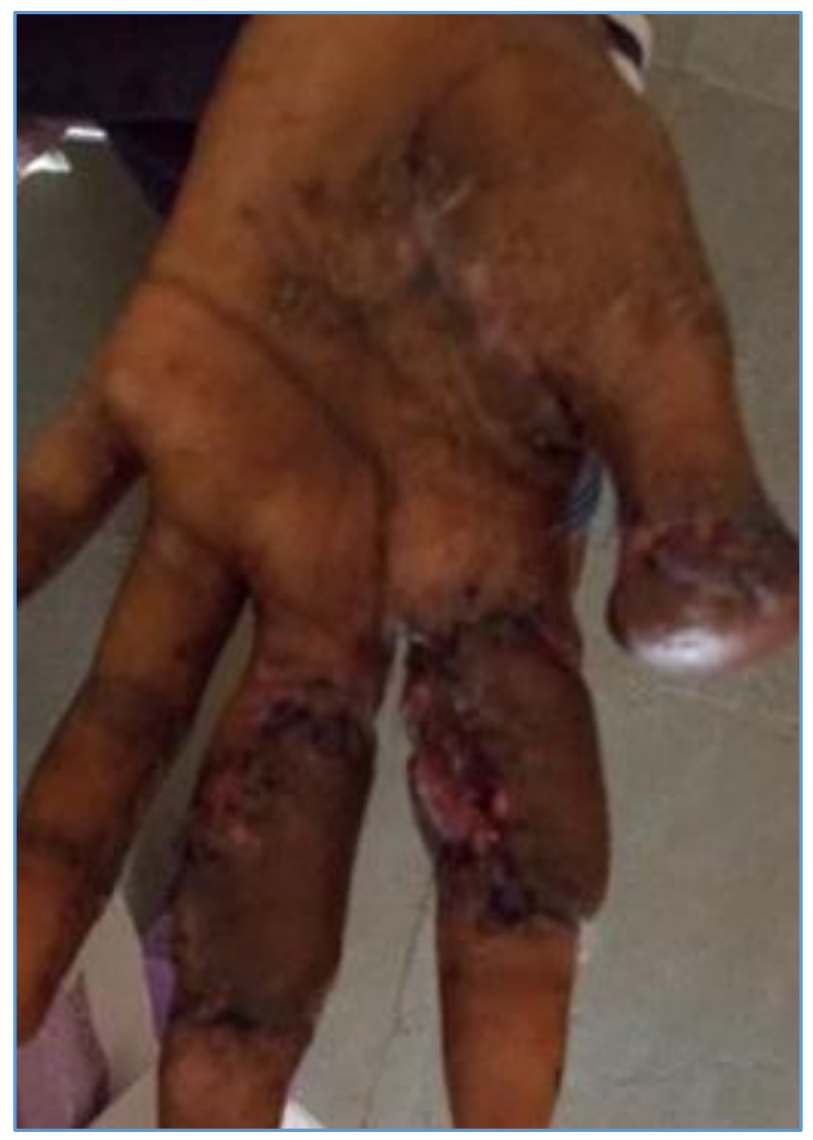

Case 2
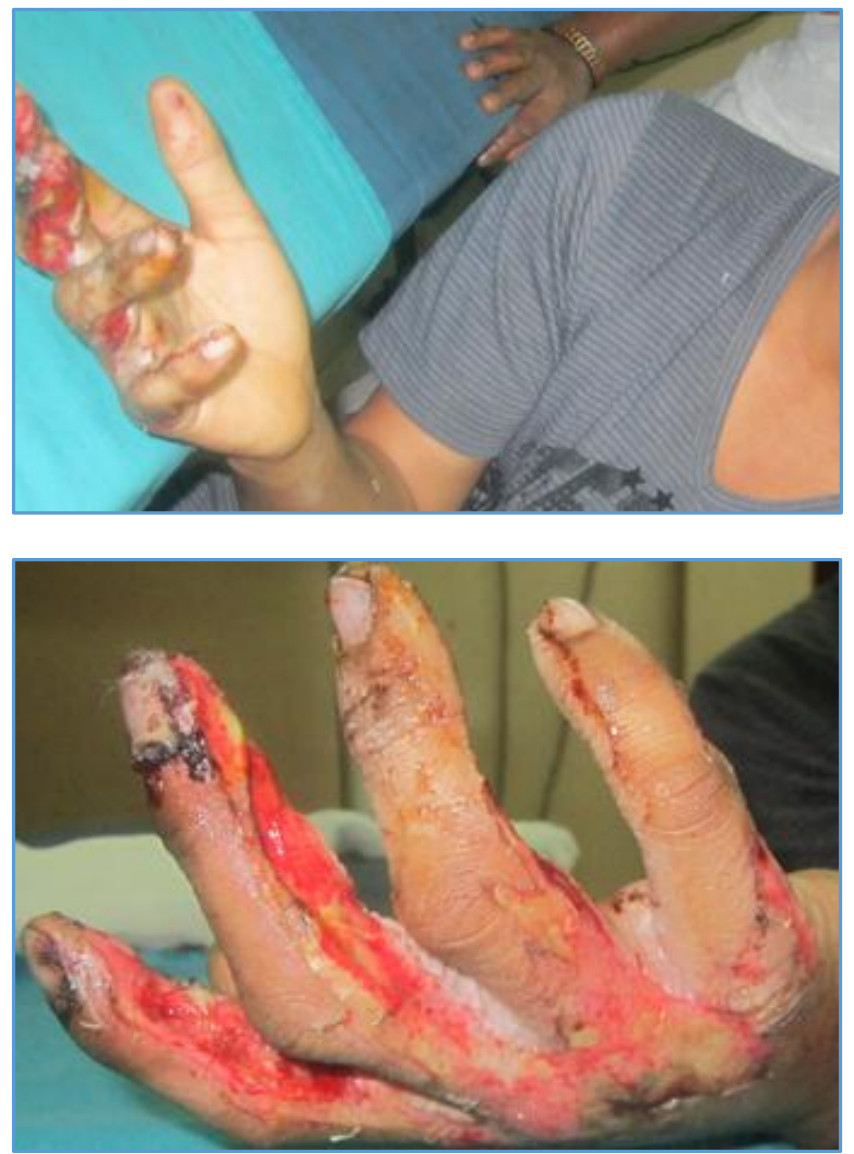

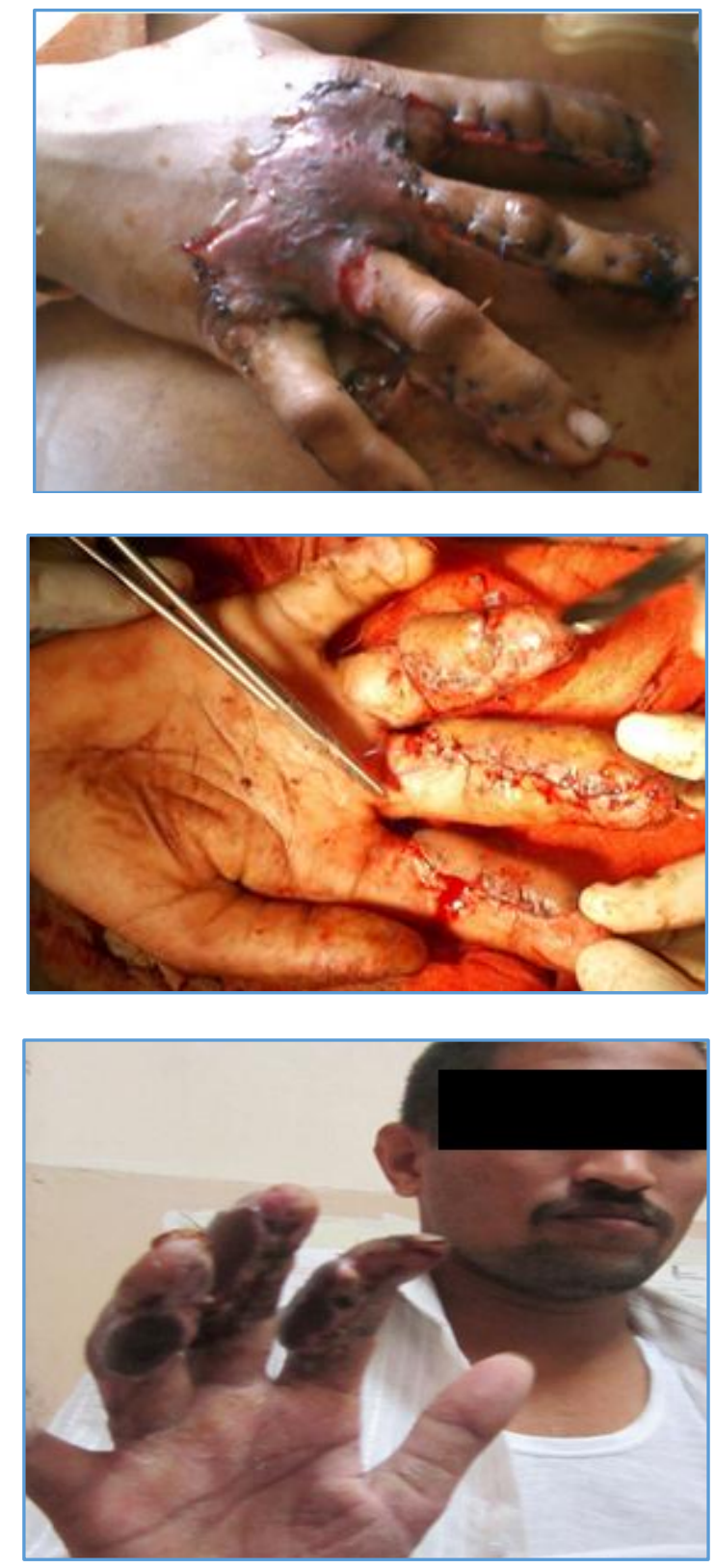

\section{Case 3}

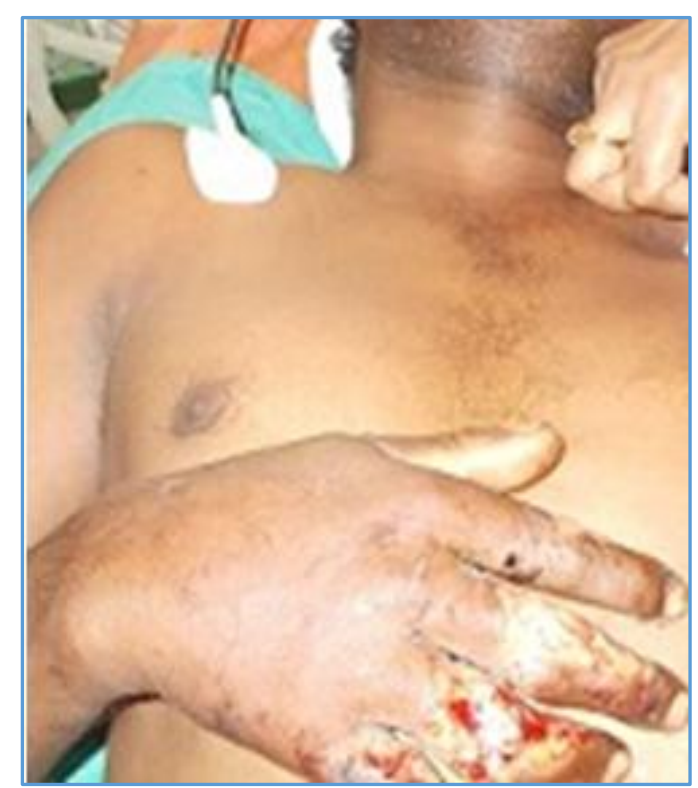

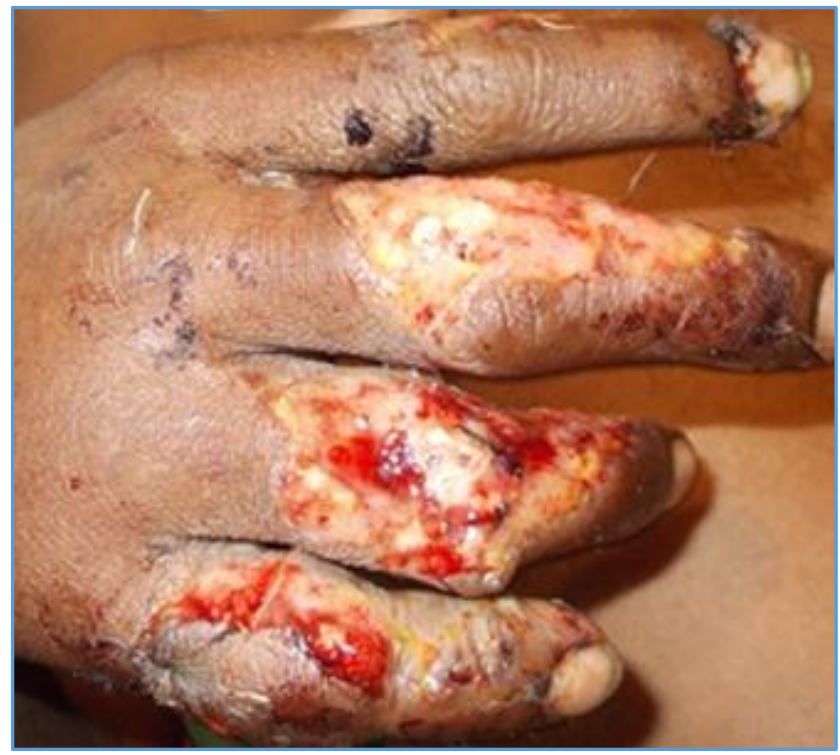
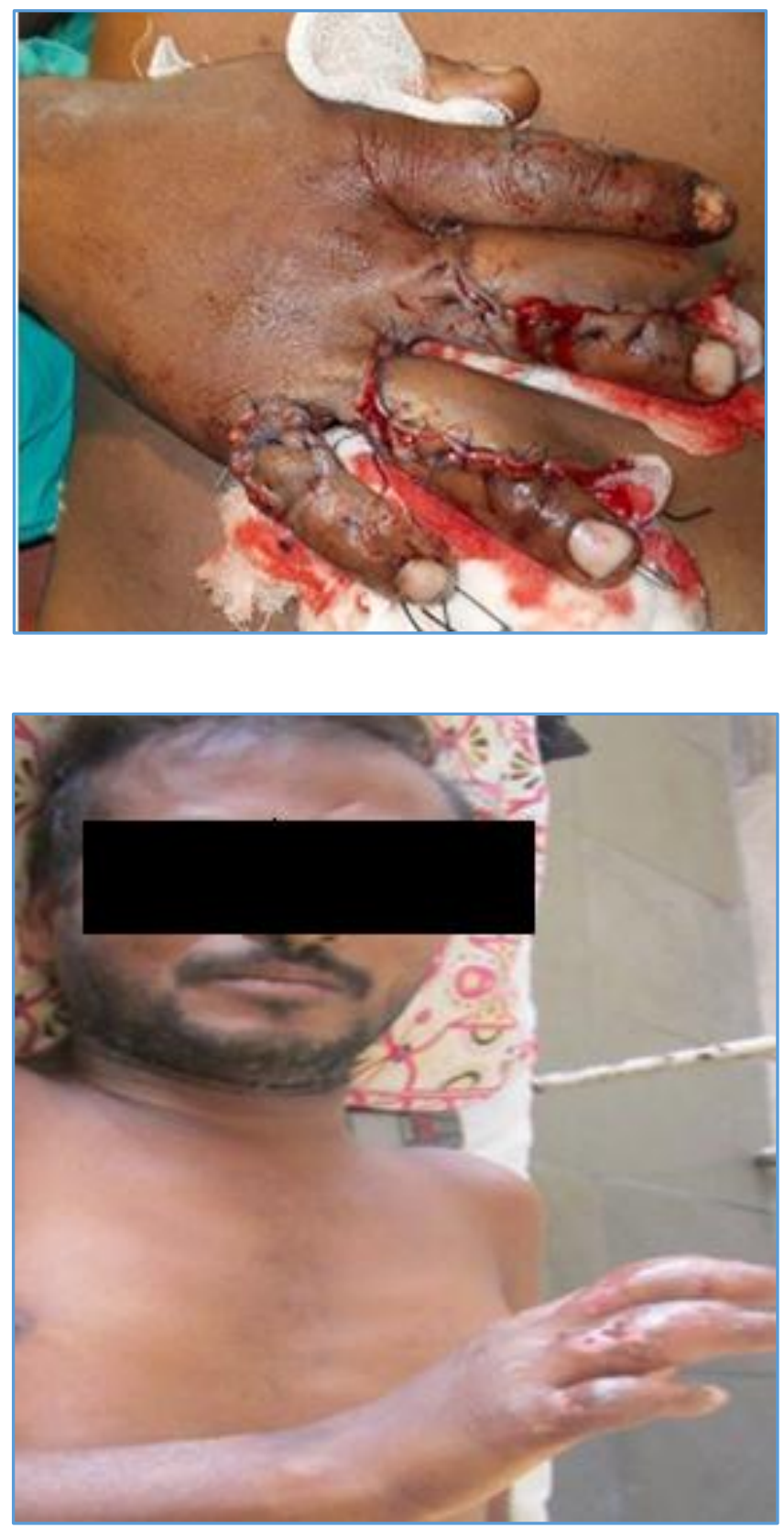


\section{DISCUSSION}

In our hospital, we commonly come across hand injuries with defects involving multiple fingers due to various causes. Most of the times, the wounds are compound exposing tendons or phalanges. These defects may or may not be associated with fractures of phalanges. We planned reconstruction of such injuries immediately to regain the early function of hand. Such defects are immediately debrided and reconstructed early with flap (Louvre) cover.

\section{We opted Louvre Flaps for Finger Reconstruction ${ }^{5}$ due to} these Reasons

- A greater surface area of cover can be provided for a number of adjacent digits by raising multiple small flaps instead of a single flap.

- Donor area defect is smaller and can be closed primarily or skin grafted.

- The resultant small scars can be managed secondarily by scar revision, making them cosmetically better and acceptable.

- Stable skin cover over the fingers subjected to friction and stresses of regular daily activities.

- The other options for finger defects ${ }^{6}$ are -

- Abdominal flaps.

- Groin flap.

- Bilobed flaps.

- Free microvascular flaps (eg: anterolateral thigh flap).

All these flaps require converting multiple defects into single defect and planning a single flap cover. Surgical syndactyly so formed requires multiple procedures such as web creation at multiple stages; flap thinning before hand regains its function. These multiple procedures delays initiation of hand physiotherapy, which is critical for hand function. These are bulky flaps when compared to Louvre flaps. Abdominal flaps leave a wide scar over abdomen. Apart from this, free flaps ${ }^{7}$ requires expertise in microvascular surgery.

\section{Limitations of Louvre Flaps}

- As with all pedicled distant flap limb immobilised for 4 - 5 weeks.

- Multiple procedures required. (Flap elevation, delay, division and scar revision).

\section{CONCLUSION}

Louvre flap is a versatile flap to cover each finger separately and simultaneously, provides more tissue than a single flap and leaves a cosmetically better donor site defect and with fast recovery of hand function.

\section{REFERENCES}

[1] Adani R, Castangnetti C, Landi A. Degloving injuries of the hand and fingers. Clin Orthop Relat Res 1995;314:19-25.

[2] Barron JN, Emmett AJ. Subcutaneous pedicle flaps. Br J Plast Surg 1965;18:51-78.

[3] Emmett AJ. Finger resurfacing by the multiple subcutaneous pedicle or louvre flaps. Br J Plast Surg 1974;27(4):370-4.

[4] Neumeister $M$, Hegge T, Amalfi A, et al. The reconstruction of the mutilated hand. Semin Plast Surg 2010;24(1):77-102.

[5] Coloson P, Houot R, Gangolphe M, et al. Utilisation des lambeaux degraisses (lambeaux greffes) en chirurgie reparatrice de la main. Ann Chir Plast 1967;12:298.

[6] Krishnamoorthy R, Karthikeyan G. Degloving injuries of the hand. Indian J Plast Surg 2011;44(2):227-36.

[7] Yu G, Lei HY, Huang JH, et al. Treatment of degloving injury of three fingers with an anterolateral thigh flap. Chin J Traumatol 2011;14(2):126-8. 